\title{
Theory-Based Instructional Models Applied in Classroom Contexts
}

\author{
Huong Pham \\ Argosy University, San Francisco Bay Area, USA
}

\begin{abstract}
There is a strong relationship between learning theories and instructional practices. Effective learning occurs as a result of effective teaching strategies. Effective teaching requires teachers to understand learning concepts and to develop a theoretical orientation combined with practice for efficient instructional design. There are three leading learning theories presented in this article, i.e., behaviorism, cognitivism, and constructivism, each of which is associated with certain types of instruction to yield productive outcomes. Direct instruction and mastery learning are the two typical models that can measure observable changes in learning behavior, a focus of behaviorism. Self-directed learning and cognitive strategies best represent cognitivism that is mainly reflected by the information processing through a series of complex procedures. Cooperative learning and service learning, on the other hand, can typically demonstrate the nature of constructivism, which places an emphasis on how students construct understanding through social interaction and negotiation of meaning. The instructional models presented in this paper are expected to support teachers to enhance teaching strategies and design effective instruction through a critical reflection of theoretical concepts and practical application.
\end{abstract}

\section{Introduction}

One of the critical factors that impacts the teaching and learning process is how to design effective instruction that can address diverse learning styles and academic backgrounds. Learning is evidenced not only in changes in behavior but also changes in cognitive processes. Effective student learning occurs as a result of effective teaching strategies, as well as teacher knowledge of the subject matter. Additionally, a teacher's clarity, stimulation of interests, and openness to opinions are other significant factors to manage learning efficiency and effectiveness [20]. Underlying all of this is the importance of the teacher's critical understanding of learning theories and how to apply them to the cognitive, motivational, and psychological learning process associated with academic success. Any productive teaching methods or activities are governed by learning theories, a distinct area in curriculum development and educational practice. In order to develop effective lesson plans to bring about the attainment of desired objectives, teachers "must possess a variety of skills and have a solid understanding of different concepts, ideas, and theories." [5, p.46] Said another way, "teachers who do not make use of a systematic body of theory in their day-by-day decisions are behaving blindly.” [3, p.5] This paper will present a number of instructional models that can be successfully applied in classroom contexts based on a holistic view of the three leading learning theories, i.e., behaviorism, cognitivism, and constructivism.

\section{The Behavioral Theories}

According to behaviorists, learning occurs as a result of observable changes in human behavior that are acquired through conditioning, a process achieved by interactions with the environment [5]. If no changes are observed in behavior, learning does not occur. From behavioral perspectives, internal and cognitive processes are invisible and cannot be studied scientifically, thus outward behavior is the key indicator of human learning. In behaviorism, there is a relationship among three factors: antecedent conditions (stimuli), behaviors (responses), and consequent conditions (rewards or punishments) [3; 19]. In this model, a response can be predicted when a stimulus is given. This might encourage teachers to use a positive stimulus (e.g., smile, praise, friendly attitude) to increase a desired response from students (e.g., hard working, motivated attitude), which may lead to a positive consequence (high achievement). Similarly, a negative stimulus (e.g., frown) can discourage an undesirable response (e.g., student talking), which can lead to a decrease in the negative behavior.

According to behavioral theories, teachers can play a significant role in effecting learning by determining what to teach with objectives based on desired behavior. In other words, there should be programmed instruction to shape responses for successful outcomes. Programmed instruction refers to "a system of teaching and learning within which preestablished subject matter is broken down into small, discrete steps and carefully organized into a logical 
sequence in which it can be learned readily by the students.” [3, p.113] Students can progress through the sequence of steps established by the teacher with the response reinforced immediately after each step. Another important element in behaviorism is the transfer of learning; in which skills, knowledge, and attitudes learned in a specific context can be transformed and applied to a new setting [27]. The transfer of learning shows the ability to connect theoretical orientation and practical application and to apply what one has achieved in the learning process to real-life situations. Behavioral theories are further demonstrated by the following types of instruction.

\subsection{Direct Instruction}

Direct instruction provides a disciplinary structure and can lead to meaningful and systematic learning experiences. It is an approach to learning where students remain engaged and focused while achieving desired learning outcomes. Direct instruction requires face-to-face environments to establish a climate for collaborative learning that enables students to comfortably share their thoughts [11]. However, because of time constraints in meeting face-to-face, students have fewer opportunities to contribute to the discussion. Teachers, therefore, often intervene to control dominance to ensure that discussions and learning activities can stay on track. To be able to keep control of the class, teachers can select to give direct answers to a controversial issue. They can also diagnose misconceptions and provide explanations to help students become aware of varying aspects of the lesson content. Teacher intervention in an appropriate manner is believed to promote students' continued engagement and academic success.

In addition, direct instruction is designed for whole-group oriented learning with an emphasis on factual knowledge. Factual knowledge is similar to declarative knowledge or verbal information since it can be expressed verbally [10]. Factual knowledge, however, is not considered a part of the hierarchy of intellectual skills for human intellectual development. Intellectual skills are believed to come from "procedural knowledge" that requires prior learning of prerequisite skills while it is not true for factual/declarative knowledge [9].

There are three broad components included in direct instruction [25]. First, direct instruction determines what should be taught and how the content should be organized based on general categories. Second, it includes specific programs to build skills by organizing lessons and planning teaching procedures in detail. Third, it specifies a clear set of procedures about how teachers and students interact. Also, there are indicators that should be used for the framework of teaching procedures in direct instruction. These procedures should include, but are not limited to, presenting content and questions, focusing discussions on specific issues, summarizing ideas, confirming understanding, diagnosing misconceptions, gaining knowledge from multiple sources, and responding to major concerns [8].

Popular methods of direct instruction include the use of lectures, video presentations, web-based demonstrations, guest speakers, controlled wholegroup discussions, and other related activities. Since these activities may take place over an extended period of time, one of the useful strategies to keep students engaged during instruction is the use of change-ups, which are brief interludes to regain student attention [20]. The purpose of change-ups is to direct student attention elsewhere and then back to the lesson to engage their focus. Change-ups must be connected with learning objectives and lesson contents. A joke or a short break is not considered a change-up as it is not related to achievement goals.

The biggest strength of direct instruction is to provide students with structure, organization, and sequence of lesson contents and learning activities from simple to complex [5]. Teachers determine specific objectives and prescribe structured learning tasks that students need to achieve to demonstrate what they have learned. Also, direct instruction is found productive in blended learning environments where students are more likely to have higher levels of connectedness when receiving "directed facilitation" toward the accomplishment of learning objectives [11]. This implies the need for teachers to be more clarifying in their assignments and instructional activities.

In addition to strengths, the limitation of direct instruction is that it offers few opportunities for student- initiated activities [27]. It is believed that too much direct instruction exploited in class can undermine student responsibility for independent learning. Too little of direct instruction, however, can initiate a loose structure and purpose of the subject matter. Nevertheless, despite a number of educators' criticism toward direct instruction as teacher control and rote learning, it has proved effective in the sense that (1) the content can be delivered to the entire class, (2) teachers provide clarity through explanations, (3) teachers control student attention, and (4) teachers focus on class objectives. As a consequence, though direct instruction can be found effective for all students, it appears most appropriate for those who need intensive controlled practice and teacher guidance. 


\subsection{Mastery Learning}

Mastery learning is a well-researched instructional model which became very popular in the early 1970s. It is based on the belief that if instruction is organized, consistently monitored, and taught in a specific way, and if students receive consistent feedback on their performance, they can master curriculum knowledge [1]. Mastery learning can yield positive outcomes if there are three active ingredients: clear mastery objectives, preestablished and high passing standards, and a criterion-referenced grading system [12]. Experienced teachers usually set clear and achievable course objectives so that all students can learn. They also support students to achieve preestablished standards of performance in a criterion-referenced manner, i.e., directly related to the attainment of specified objectives and assessment criteria, no matter how well other students are performing.

In mastery learning, prior knowledge serves as a prerequisite foundation for subsequent learning, thus one is required to master a basic lesson or unit exam before proceeding to a more complex one [7]. This places an emphasis on sequentially structured instruction. Students who do not achieve the required mastery level have to receive remediation through tutoring, peer monitoring, small group discussions, and/or additional assignments. They have to learn and relearn and continue the cycle of studying and testing until the mastery standard of performance is met. When students reach the mastery level, their knowledge and skills will certainly go beyond the initial performance. For this reason, mastery learning requires a very high quality of instruction as learning objectives must be attainable for all students who are encouraged to catch up with new procedures for improved academic performance.

Whatever is taught, teachers should be aware that students need to master fundamentals as a criterion for passing the expected standard. To ensure student mastery of knowledge, teacher feedback is of critical importance in student progress. The feedback should be based on formative assessment during instruction rather than a summative grade or test score at the end of a course [18]. Students should compare and contrast both correct and incorrect concepts and follow correction procedures to understand subject components more thoroughly and maximize learning outcomes.

In order to create effective mastery learning, teachers should take into account the following factors:

- Instruction should be broken down into small and manageable parts.
- Units should be presented in a logical sequence from concrete to abstract as a basis to achieve more complex tasks.

- Students can demonstrate content mastery through testing or formative assessment.

- Teachers have to provide concrete objectives and guided instruction for student mastery of knowledge.

- Additional or specially-designed activities are needed to help remedial students to correct misunderstanding [30].

Adopting instruction to student prior knowledge, however, is not that simple because students remember differently from prior instruction and they may hold different conceptions when learning or relearning at different rates [18]. Critics of mastery learning also point to the fact that teachers often teach and direct student attention to achievement tests. This may lead to increased learning outcomes but fail to give students an overall view of the subject matter, thus making their understanding become narrow in a behavioral and structured situation [1]. Also, in mastery programs, competent students have to wait for slow students to catch up, for which the former can receive much less information and lose their interests [12]. Additionally, there is not much interaction between teachers and students or among students themselves.

Despite controversies over negative aspects of mastery learning, many school systems believe that the implementation of mastery learning with corrective techniques can lead to striking academic improvement [9]. Mastery learning is beneficial to high-level students as well as low-level students since they must demonstrate their competence on the required standard of performance. It is also found most useful for slow students with basic skills [7]. While high-level students tend to get a higher score on the test and master the subject matter more quickly, lowlevel students are also considered successful in passing the standard, despite lower grades. It also supports the fact that learning should be based on a specific standard and passing this standard is recognized as certification of competence. By this way, all students feel encouraged to study in a facilitative environment where they can receive constructive feedback and correction procedures for increased academic success.

\section{The Cognitive Theories}

Different from behaviorism, cognitivism considers learning as a change in cognitive thinking and focuses on internal mental processes that change the way people conceptualize, realize, and understand their environment [5]. Cognitivism is believed to make 
useful inferences about mental processes that manage and determine behavior. In cognitivism, the learning foundation is based on human memory. If there is no memory, there can be no learning and without learning, memory becomes an empty vessel [1] However, understanding knowledge that takes place in the brain is not easy as there is no simple way to observe activities that mentally occur. Cognitive psychologists, therefore, have turned their attention to careful observation and examination of human memory, learning, and problem solving to explain mental processes.

Cognitive learning emphasizes social interactions, a purposeful relationship among individuals and their perceived environment. In social interactionism, individuals are considered not passive objects but interactive and intentional subjects who interact with the environment based on combined thought and behavior [3]. They try to give meaning to their environment and behave not as an automatic device but as a thoughtful and purposeful being. The goal of cognitive learning is "to develop student academic and thinking skills from a novice level to a more expert level....[and] to provide adequate experiences in which students structure the learning and teaching themselves.” [27, p.38]

One of the important factors in cognitive teaching is to foster student motivation to become active learners through interactions with the environment. The primary method that incorporates cognitive ideas into teaching is the employment of information processing, which refers to how information is learned, modified, or changed [19]. Its emphasis is on perceptual and conceptual processes that allow the learner to perceive and determine functions of recognition, memory, and problem solving. This procedure is quite similar to a computational system that processes information from concrete to abstract, simple to complex events, and to provide learners with multiple examples to reinforce the organized information [30]. Learning finally occurs as a result of the learner's adaptability of internal functions that create new experiences. The following types of instruction may best represent the nature of cognitive theories.

\subsection{Self-Directed Learning}

Self-directed learning aims to develop student autonomy and requires students to take responsibility for their own learning to reach desired outcomes. As defined, self-directed learners are "in a continuous learning mode... always striving for improvement, always growing, always learning, always modifying and improving themselves. They seize problems, situations, tensions, conflicts, and circumstances as valuable opportunities to learn." [6] As autonomy is the cornerstone of self-directed learning, it is more appropriate for adult learners who are considered capable of self-managing and self-modifying their learning than children [17]. Adult learners usually set clear goals, develop strategies, and control their actions and behaviors to achieve the goals. They know how to confront problems with confidence and strategic approaches, monitor problem-solving strategies, and apply different alternatives if learning outcomes are not as expected. They learn from their real-life experiences, modify their responses, and apply learned principles to novel situations. Among essential abilities found in self-directed learners are the abilities to engage in divergent thinking; to formulate questions and locate sources of data to answer the questions; to organize, analyze, and evaluate the data; and to generalize and communicate the answers to the audience [31].

The bottom line in self-directed learning is to offer students the practice of independent study so that they can take an active role, generate ideas, and seek meaning in the learning process rather than react to teacher stimuli. Self-directed learning can be promoted both inside and outside the classroom. Primary methods inside the classroom include small group learning, open discussions, role-playing, case studies, and student presentations. While activities are occurring, teachers make observations and walk around giving support when necessary as facilitators in the learning process. Methods outside the classroom include experiential learning, fieldwork, and science projects, all of which can increase student higher-order learning and intellectual skills [20].

Self-directed learning can be further strengthened by setting appropriate goals, developing intrinsic motivation, and giving feedback to learners for evaluation and monitoring of self-direction [32]. Also important is to integrate self-directed learning and practice. Effective self-direction takes place when learners have access to authentic tasks and expert guidance and to participate in social contexts for skill development [29]. Self-directed learning should be conducted through the integration of "off-the-job" and "on-the-job" learning to comprehend theoretical concepts that can foster practical experiences, as well as a set of principles that can be used at work.

In a research study on self-directed learning, the findings indicated that self-directed learners mainly have two characteristics: learning needs and motivational control [33]. Identifying a learning need is of worthwhile consideration as it initiates motivation for learning. Only if learners have a great need of achieving something will the self-directed learning effectively take place. Motivational control, on the other hand, refers to efficient learning strategies 
that control the learning process. This requires the planning and selection of leaning strategies that act as self-regulatory keys to independent learning. These controlling strategies are conceived as motivational control because they refer to individual motivation to self-regulate learning to reach predetermined goals. The more learners are highly motivated, the more they are self-directed and thus modify strategies accordingly to make learning a success.

There are three primary motivators that are believed to motivate self-directed learners substantively: importance, efficacy, and emotional response [22]. Importance refers to the knowledge which is perceived as instrumental in satisfying a basic need or achieving a personal goal. Self-directed learners choose important subjects to study rather than all kinds of information. Efficacy refers to the belief that self-directed learners have sufficient ability, power, and/or resources to gain competence in the field. If a learner is doubtful of his/her ability, it will lessen the motive to learn. Finally, emotional response strongly affects the motivation. That a learner has a high or low level of emotion is a powerful influence on his/her motivation that guides the action in a given setting to make self-directed learning occur.

In order to develop effective self-directed instruction, teachers should emphasize individual and small group work for discussions and team projects. Teachers should also place a focus on student exploration and student-centeredness and invest a large amount of time in planning self-directed learning tasks [27]. Additionally, teachers can facilitate selfdirected learning by providing students with effective learning strategies. These strategies should involve students in sharing examples of successful learning methods with each other. Sharing information about what works and what does not work helps students refine their own methods and adopt potential approaches for greater academic success. Teachers also need to direct student attention to the importance of not just working hard but working strategically to achieve desired goals with the least time and efforts. Moreover, guidelines for self-directed learning should emphasize the need to change strategies in different contexts for different purposes. Working strategically should be addressed as an opportunity for students to develop a volitional spirit and controlling strategies to cope with challenges [23].

Self-directed learning should be applied to schooling to promote student responsibility for learning as well as to real-life contexts to help students keep informed about updated information and social trends. When considering adopting self-directed instruction, teachers should note with caution that a number of programs are highly structured and there are strict academic standards defined as learning objectives that students have to acquire [27]. Teachers should also equip students with right actions and strategies to implement and control their own learning as learning is a lifelong process that needs a great sense of autonomy and accountability for the development of intellectual skills and lived experience [32].

\subsection{Cognitive Strategies}

Cognitive strategies are of "a control process, an internal process by which learners select and modify their ways of attending, learning, remembering, and thinking.” [10, p.74] Cognitive strategies support learners to develop internal processes that enable them to perform complex tasks. These strategies typically refer to Bloom's taxonomy of the cognitive domain with six levels from simple to complex: knowledge, comprehension, application, analysis, synthesis, and evaluation. This is considered a hierarchy of the mental process that addresses different learning outcomes at different levels, each of which has to be mastered before moving on to the next one. The ability to think, for example, is fostered not only through the recall of knowledge but also the synthesis and evaluation of collected information. Professional educators usually stress higher levels of learning as a central premise in teaching to orient students to the complexity of the cognitive process for intellectual development [26].

Different types of learners use different cognitive strategies to achieve learning tasks. Typical cognitive strategies commonly used include (1) rehearsal strategies, (2) elaboration strategies, (3) organizing strategies, (4) transformation strategies, and (5) comprehension monitoring strategies. Rehearsal strategies require learners to conduct practice of target information through verbalization, visuality, audiolingual study, or other means repeatedly until reaching a desired level. Elaboration strategies refer to the techniques in which students expand target information by relating other information to it [10]. This connection can enhance the efficiency of thinking and memorization. Elaboration strategies require the simplest version of the task to be presented first, followed by subsequent complex lessons until the full task is completed. A key idea of elaboration strategies is that teachers need to develop a meaningful context that involves the learning of fundamentals or representative ideas at the application level. Examples of elaboration strategies include paraphrasing, notetaking, summarizing, and generating questions with answers.

Organizing strategies, as the name suggests, requires that learners categorize or sequence information for more efficient recall or use of 
knowledge. Teachers should also organize teaching materials or tasks to support students to develop effective organization skills and accomplish the tasks toward achieving ultimate goals. Transformation strategies, on the other hand, ask students to simplify target information by converting difficult or unfamiliar information into manageable information [16]. When experiencing challenging concepts, students should transform them into comprehensible inputs through the application of information processing for learning efficiency. Transformation strategies give students opportunities to identify and articulate underlying assumptions, alternative ideas and approaches, as well as to test and apply new perspectives. Teachers, in an attempt to enhance student transformation learning, should (1) trigger students to examine and explain their thinking, (2) encourage critical reflection and discourse, (3) give students opportunities to test a new paradigm, and (4) foster intellectual openness [21]. By this way, teachers can provide necessary support and challenge for effective transformation learning to occur.

Different from the other four, comprehension monitoring strategies, sometimes referred to as metacognitive strategies, are to monitor and manage one's own learning to meet predetermined goals [10]. Metacognition is considered the practice of "thinking about thinking" and "a reflective process that helps improve an individual's control over his or her thinking process and learning.” [5, p.32] A critical component of metacognition is the employment of study strategies, self-assessment, and self-regulation to reach expected outcomes. This arena is much similar to the self-directed learning as mentioned before. One of the methods to enhance the effectiveness of metacognitive strategies is to "make knowledge visible by having students verbalize their thinking while they solve problems.” [14, p.86] Since cognitive strategies cannot be observed directly, verbalizing student thinking helps teachers aware of students' understanding of a concept and their readiness levels. Another method is to share teacher thinking with students, which should focus on the ways of how to identify a problem, approach it, and make choices of possible solutions to work it out.

Teachers can make use of the above cognitive strategies to support the cognitive learning process. Decisions on which specific strategies to use would be based on student needs and readiness levels. Lowachieving students may need to understand and apply what they learn to a new context without the need of questioning. High-achieving students, however, may tend to apply metacognitive strategies for selfregulation through the analysis, synthesis, and evaluation of existing information. Cognitive strategies can increase student motivation through the creation of meaningful learning contexts and the transformation of information that allows student control and autonomy.

\section{The Constructivist Theories}

Constructivism, a variant of cognitivism, is based on the belief that "an individual constructs his or her understanding of the world in which he or she lives by reflecting on personal experiences.” [5, p.37] Learners are not supposed to wait for knowledge to be filled but play an active role to seek meaning and nurture selfawareness. When encountering a principle, concept, or phenomenon that does not make sense, learners often interpret or generate new rules to comprehend ideas. They can develop different interpretations about similar things based on their living environments and interactions with others. In other words, human understanding is contextually embedded and interpersonally influenced by the living environment.

According to constructivist perspectives, learning occurs when individuals are actively engaged in the learning process and integrate new knowledge with existing knowledge [3]. Learning is considered an active process of constructing rather than receiving knowledge. Also, teaching is considered a process of supporting learners to construct ideas rather than delivering knowledge. When applying constructive strategies, teachers may start with the information that students know and lead them to new knowledge by using thought-provoking questions and scaffolding techniques [26]. Scaffolding refers to a spiral instructional model that provides extensive support and a framework of sequential lesson contents to gradually build up students' understanding of new concepts based on their prior knowledge [10].

In constructivism, social communities have a strong impact on constructed meaning, thus initiating the term social constructivism [3]. Social constructivism emphasizes the important role of social and cultural contexts that help transform and share meaning among groups of people. Said another way, without social interactions and interdependent relationships, learners cannot construct understanding. This principle encourages a teaching approach that should emphasize the social interaction in a sense that it can engage learners in learning tasks and optimize learning outcomes [32]. Among the learning models germane to constructivist theories are cooperative learning and service learning as indicated below that all help build up learner understanding of disciplinary areas through team collaboration, everyday communication, and the application of academic knowledge to real-life situations. 


\subsection{Cooperative Learning}

Cooperative learning is considered a typical model that can maximize the effectiveness of constructivism. It is a teaching strategy that employs small-group assignments to accomplish shared goals. Cooperative learning is also recognized as an effective method that can promote socialization and enhance student willingness to work with others with diverse learning needs and sociocultural backgrounds [13]. When students work collaboratively, they learn to listen to what others say and how people say it, discuss issues, share ideas and perspectives, seek ways of resolving problems, giving and receiving support, and actively work to construct new understanding and learning.

At its best, cooperative learning is strongly related to motivational issues, accountability for individual and team success, and a deeper understanding in a spirit of mutual support and trust building [15]. When the connectedness in learning is adopted with respect, "it creates a climate in a learning group that invites adults to access their experience, to reflect, to engage in dialogue, and to allow their histories to give meaning to particular academic or professional knowledge- all of which enhance motivation to learn.” [32, p.104] It is no doubt that cooperative learning offers a multitude of benefits to students in terms of (1) improving academic achievement, (2) enhancing student enthusiasm and determination to achieve success, (3) improving interpersonal relations and problem solving skills, and (4) fostering student emotional well-being and self-esteem [27, 32].

There are five core principles that teachers should take into account to initiate cooperative learning [30]:

- Positive interdependence: Different from traditional classrooms where students often develop a spirit of competition, cooperative learning encourages students to work together and emphasizes individual achievement as well as team success.

- Face-to-face interaction: As cooperative learning places an emphasis on interaction, students need to interact, assist others with learning tasks, and share opinions for the achievement of desired goals.

- Individual and group accountability: Students are held responsible for their individual progress and task completion to achieve group objectives.

- Social skill development: This is one of the most critical factors of cooperative learning. It offers students exposure to develop interpersonal skills at schools, at work, and in communities.

- Group evaluation: This strategy keeps students informed about how well they perform during instruction. Group evaluation helps students respond to problems arising from the learning process and adjust learning strategies to better achieve learning outcomes.

Cooperative learning structures vary tremendously and are simple or complex depending on students' academic levels. Initiating cooperative learning is not simply a matter of placing students in groups and assigning tasks. Instead, it requires teachers to get involved in a wide range of professional tasks rather than teaching. It requires teacher competence to carefully categorize students into groups with similar characteristics, set feasible objectives, plan appropriate activities, and monitor individual progress. It also requires teachers to give feedback on student performance on a regular basis for academic improvement. Feedback is important for academic success and should be detailed, specific, goal-oriented, and unbiased. When students do not make sense of a given concept or fail to follow directions, it is the teacher's responsibility to provide them with intensive support or clarification [27].

Academic success also depends on teacher preparation to guide students how to operate in each group to promote their satisfaction with learning experience. Teachers should play the role as "the guide on the side", who facilitates student learning by not directly getting involved in learning tasks and strategies but providing support when necessary. With this role, teachers can challenge student thinking and scaffold their understanding to help construct new ways of thinking and learning. Additionally, teachers should offer students opportunities to get engaged in different types of learning activities not only related to achievement tests but also to research topics, discussions, presentations, debate activities, science projects, experiments, etc. Teachers should also dialogue with students to motivate their interests, shape their potential strengths, and keep them informed about what tasks they are supposed to do and what responsibility they have to share with team members for individual and team success. Effective teachers are believed to engage higher student participation, ask more provoking questions, emphasize higher-order intellectual skills, and approach students more closely as opposed to telling them what to do [13].

It is no doubt that "many traditional socialization practices are absent. Not all students come to school with a social orientation.” [30, p.223] Therefore, teachers are encouraged to apply cooperative learning as it allows students to become active recipients of knowledge and to experience the subject matter content as viewed from multiple perspectives. This is one of the vital steps to develop social orientation and cognitive thinking for the attainment of individual and team success. 


\subsection{Service Learning}

One desirable goal of teaching is to connect classroom teaching with practical experience. Service learning, also called experiential learning, refers to "the involvement of learners in concrete activities that enable them to 'experience' what they are learning about and the opportunity to reflect on those activities. Experiential learning can be based on both real work/life experiences and structured experiences that simulate or approximate real work/life." [28, p.8] Service learning calls for the integration of theory and practice, knowledge and experience to link the course content to real-life contexts. Service learning, therefore, is considered a process in which knowledge is created through the transformation of experience. The foundation of learning is the interaction between an individual and the external environment. In other words, knowledge and experience are closely intertwined and almost inseparable. It is meaningless to talk about learning in isolation from experience, which is the central consideration of all forms of learning [2].

Unlike other types of learning that are mostly conducted in class, service learning is not confined to a traditional class meeting but builds upon accumulated powerful events such as field experience, community service, action learning, internship, and other work practices [20]. Additionally, though there have been a variety of learning theories developed in educational psychology, they are found isolated from one another and there is no overall coherence among them. The great advantage of service learning is to provide an underpinning framework that acts as a thread joining learning theories together in a unified whole [2]. In service learning, finding and defining problems as well as troubleshooting are integrated skills that students can master to enhance conceptual models for the construction of systems knowledge. The integration of learning and experience can help students relate to underlying principles and theoretical concepts to enhance the understanding of curricular components.

Benefits of service learning are also evidenced by exposing students to social issues and community service to become active responsible citizens. This exposure positively impacts the development of academic skills, life skills, citizenship, and human values. Also, the engagement in collaborative activities helps students develop their own beliefs and values. Students can acquire multiple skills and career experiences that can strengthen academic and professional knowledge. Through these experiences and reflections on them, students can construct new understanding accordingly and apply it to a specific setting.
A quality service learning program is expected to provide valuable job training and work experience to students through the teaching of general workplace skills and job skills related to a specific major [20]. It also assists students to seek employment and select a career major through integrated academic and vocational curriculums. The success of service learning is to see students develop academically, socially, and emotionally and extend their reach to a larger society and demonstrate a greater understanding in cultural and racial aspects [24].

One of the key aspects of service learning is that it helps change student attitudes and behaviors through a five-stage process: creating openness, promoting understanding, considering new attitudes and behaviors, experimenting, and obtaining support [28]. Creating openness is to get students to voice their opinions and concerns towards new ideas. Students may be resistant to change if their concerns are not well taken. Once students are open to examining their beliefs, as well as to hearing feedback on new information, they can develop a better understanding of it. Then they can take into account new attitudes and behaviors and make changes in the way they see things. This stage can be implemented through the use of varying experiential methodologies (e.g., role-plays, games, simulations, videos, problem-based learning) for students to consider and adopt new ideas. Experimenting is the next stage to support students to experience the new idea by having it applied or transferred to a new situation. This provides the opportunity for students to test new knowledge and perspectives. Students may use their newly acquired knowledge and theoretical constructs to make decisions and solve problems. The last stage is to offer necessary support if there are any difficulties students have experienced. In order to implement this learning process, it requires the teacher to act the role as a facilitator to make successful changes in student attitudes and behaviors for service learning to take place efficiently.

Service learning is obviously a powerful teaching method that presents students with compelling and complex real world experiences, examples, and case studies. It can be effectively implemented if there is an encouragement of student personal development and social engagement. However, as concerned nowadays, service learning highlights the issue of insufficient integration of curriculums and work skills. Traditional classroom models have separated theory from practice and created irrelevant instruction that fails to bring about expected outcomes [4]. As a result, students are unable to react to changes and to construct generative processes, as well as poorly prepared for their career paths. These factors strengthen the need to make innovations and to include practical training in 
curriculums as a way to equip students with work skills for career success in an increasingly competitive society.

\section{Conclusion}

Behaviorism, cognitivism, and constructivism are the three leading learning theories addressed in educational psychology. As students have diverse learning styles and academic backgrounds, teachers should develop instruction that can reflect combined characteristics of these three learning theories. At times teachers should apply direct instruction for those who may need intensive support; at times they should employ mastery learning when there are specific academic standards that students are required to attain; at other times self-directed learning turns out effective to develop student autonomous learning habits. The use of cognitive strategies, on the other hand, can be employed when there is a need to develop students' intellectual skills and cognitive learning. Cooperative learning, in addition, can be adopted when the enhancement of communication skills or problemsolving skills is the main goal of a course syllabus. Service learning, with an aim to promote students' civic engagement, serves as a foundation to connect students to the real world setting. Service learning also contributes to the achievement of desired goals through the knowledge transformation and application process. No theories have been found superior to the others, thus the quality of instruction largely depends on how well teachers can identify students' readiness levels and learning styles and match them with relevant choices in instructional design.

\section{References}

[1] Ashman, A., \& Conway, R. (1997). An introduction to cognitive education: Theory and applications. New York, NY: Routledge.

[2] Beard, C., \& Wilson, J. (2006). Experiential learning: A best practice handbook for educators and trainers (2nd ed.). Philadelphia, PA: Kogan Page.

[3] Bigge, M., \& Shermis, S. (2004). Learning theories for teachers (6th ed.). Boston, MA: Pearson.

[4] Brook, C., \& Lock, G. (2010). Reflective practice, professional learning, and educational partnerships: Effecting change in classroom settings. In E. Ng (Ed.), Comparative blended learning practices and environments, (pp. 188- 203). Hershey, PA: IGI Global.

[5] Brown, A., \& Green, T. (2006). The essentials of instructional design: Connecting fundamental principles with process and practice. Upper Saddle River, New Jersey: Pearson.
[6] Costa, A., \& Kallick, B. (2004). Assessment strategies for self-directed learning. Thousand Oaks, CA: Sage.

[7] Davis, D., \& Sorrell, J. (1995). Mastery learning in public schools. Retrieved May 27, 2011, from http://teach.valdosta.edu/whuitt/files/mastlear.html

[8] Duffy, T., \& Kirkley, J. (2003). Learner-centered theory and practice in distance education: Cases from higher education. Mahwah, NJ: Lawrence.

[9] Gagné, R. (1988). Mastery learning and instructional design (chap. 4). Retrieved October 25, 2010, from http://www.ibstpi.org/Products/pdf/chapter_4.pdf

[10] Gagné, R., Wager, W., Golas, K., \& Keller, J. (2005). Principles of instructional design (5th ed.). Belmont, CA: Wadsworth.

[11] Garrison, D., \& Vaughan, N. (2008). Blended learning in higher education: Framework, principles, and guidelines. San Francisco, CA: John Wiley \& Sons.

[12] Gentile, J., \& Lalley, J. (2003). Standards and mastery learning. Thousand Oaks, CA: Sage.

[13] Gillies, R. (2007). Cooperative learning: Integrating theory and practice. Thousand Oaks, CA: Sage.

[14] Innes, R. (2004). Reconstructing undergraduate education: Using learning science to design effective courses. Mahwah, NJ: Lawrence.

[15] Jacob, E. (1999). Cooperative learning in context: An educational innovation in everyday classrooms. Albany, NY: State University of New York Press.

[16] Jordan, L. (2005). Special connections: An introduction to cognitive strategies. Retrieved June 1, 2011, from http://www.specialconnections.ku.edu/cgi-

bin/cgiwrap/specconn/main.php?cat=instruction\&section=cs /main

[17] Knowles, M. (1980). The modern practice of adult education: From pedagogy to andragogy (rev. ed.). Chicago, IL: Follett.

[18] Lalley, J., \& Gentile, J. (2009). Classroom assessment and grading to assure mastery. Theory Into Practice, 48(1), 28-35.

[19] Lefrançois, G. (2000). Theories of human learning: What the old man said (4th ed.). Belmont, CA: Wadsworth.

[20] Lyons, R., McIntosh, M., \& Kysilka, M. (2003). Teaching college in an age of accountability. Boston, MA: Pearson.

[21] McGonigal, K. (2005). Teaching for transformation: From learning theory to teaching strategies. Retrieved May 20, 2011, from http://www.stanford.edu/dept/CTL/cgibin/docs/newsletter/transformation.pdf 
[22] Marzano, R., \& Kendall, J. (2008). Designing and assessing educational objectives: Applying the new taxonomy. Thousand Oaks, CA: Sage.

[23] McKeachie, W., \& Svinicki, M. (2006). McKeachie’s teaching tips: Strategies, research, and theory for college and university teachers. Boston, MA: Houghton Mifflin.

[24] Meyers, S. (2009). Service learning as an opportunity for personal and social transformation. International Journal of Teaching and Learning in Higher Education, 21(3), 373381.

[25] Moran, D., \& Malott, R. (2004). Evidence-based educational methods. San Diego, CA: Elsevier.

[26] Oliva, P. (2009). Developing the curriculum ( $7^{\text {th }}$ ed.). Boston, MA: Pearson.

[27] Orlich, D., Harder, R., Callahan, R., Trevisan, M., \& Brown, A. (2004). Teaching strategies: A guide to effective instruction (7th ed.). Boston, MA: Houghton Mifflin.

[28] Silberman, M. (2007). The handbook of experiential learning. San Francisco, CA: Pfeiffer.

[29] Smith, P., \& Sadler-Smith, E. (2006). Learning in organizations: Complexities and diversities. New York, NY: Routledge.

[30] Taylor, G., \& MacKenney, L. (2008). Improving human learning in the classroom: Theories and teaching practices. Lanham, MD: Rowman \& Littlefield.

[31] Tennant, M. (1998). Psychology and adult learning (2nd ed.). New York, NY: Routledge.

[32] Wlodkowski, R. (2008). Enhancing adult motivation to learn: A comprehensive guide for teaching all adults (3rd ed.). San Francisco, CA: John Wiley \& Sons.

[33] Wosnitza, M., \& Nenniger, P. (2001). Perceived learning environments and the individual learning process: The mediating role of motivation in learning. In S. Volet \& S. Jarvela (Eds.), Motivation in learning contexts: Theoretical advances and methodological implication (pp.171-187). Kidlington, OX: Elsevier. 